\title{
Profesionalismo en el ejercicio de la Radiología
}

\author{
Dra. Karla Moënne B.
}

Comité de Ética. SOCHRADI. Santiago, Chile.

Existen múltiples definiciones de profesionalismo, entre las cuales destaca el diccionario de la lengua inglesa de Oxford que lo define simplemente como "la competencia o destreza esperada en un profesional", que respecto de los profesionales médicos constituye un conjunto complejo de responsabilidades determinadas por las expectativas de la sociedad en relación a un "buen médico"; también se ha considerado el profesionalismo como "la base del contrato de la Medicina con la Sociedad".

Se definen tres principios fundamentales del profesionalismo médico, comunes a los quehaceres médicos más diversos:

1. Principio de primacía del bienestar del paciente, que se basa en la dedicación a servir los intereses del paciente y contribuye a la confianza fundamental de la relación médico-paciente. El mercado, las presiones sociales y las exigencias administrativas no pueden afectar este principio.

2. Principio de autonomía del paciente, que obliga a los médicos a respetar la libertad del paciente, actuando honestamente y dándoles la capacidad para tomar decisiones informadas sobre sus cuidados, ateniéndose a prácticas éticas.

3. Principio de justicia social: La profesión médica debe promover justicia en el sistema de atención de salud, incluyendo la distribución equitativa de los recursos asistenciales.

El profesionalismo es una de las seis competencias principales utilizadas para evaluar médicos aprendices en todos los programas de residencia acreditados por el Accreditation Council for Graduate Medical Education (ACGME), en los Estados Unidos.

Es importante mencionar que las obligaciones de profesionalismo pueden entrar en conflicto con los intereses personales del médico, por lo que todo médico en su práctica diaria debe permanecer consciente de los intereses del paciente, intereses médicos y potenciales conflictos de interés.

En el año 2006, en la Revista Médica de Chile se reflexionaba sobre ¿Qué se puede esperar de la relación entre el médico y el paciente en el siglo XXI?, comentando que la concepción de la economía, casi como una religión, y la degradación de la dignidad humana en aras de una eficiencia que valora sólo algunos elementos de la relación médico-paciente podrían llevar a considerar la medicina como una empresa productiva más, con resultados fácilmente medibles en términos numéricos, pero no así en calidad humana y relaciones interpersonales. Sobre la base de lo anterior, se planteaba que el ejercicio de la medicina como profesión se vería seriamente amenazado de extinción por la proliferación de oficios asalariados con alto contenido científico tecnológico; en este pesimista escenario, la profesión médica debería rescatar desde sus orígenes las virtudes ancestrales que, en versión secularizada se denomina como "profesionalismo", que integra y hace relevantes los valores más tradicionales del quehacer médico, destacando un ejercicio profesional genuinamente humanitario.

A nosotros nos ha correspondido desarrollar nuestra especialidad en el siglo XXI, por lo que debemos detenernos a reflexionar si estamos cumpliendo con los tres principios fundamentales del profesionalismo médico en la práctica de nuestra especialidad, la Radiología. Como consecuencia de la innovación tecnológica, en la actualidad los Departamentos de Radiología se han posicionado como un recurso fundamental para confirmar o descartar las hipótesis diagnósticas de los médicos tratantes, que confían en la innegable importancia de las imágenes diagnósticas y en el trabajo de los radiólogos, que tienen además la responsabilidad ética con el paciente representado en las imágenes y con el colega que los interconsulta en el proceso de atención y sanación de algún paciente.

La atención de nuestros pacientes comienza cuando el médico tratante requiere un examen de imagen para alguno de ellos, gatillando un proceso en el que el radiólogo debe cooperar en elegir el 
examen apropiado e indicado para la condición del paciente, respetar el proceso del consentimiento informado cuando corresponda, vigilar adecuadamente la seguridad y protección del paciente en la ejecución del examen o procedimiento para después interpretar adecuadamente las imágenes teniendo siempre presente la condición clínica del paciente. Finalmente, debe asegurarse una comunicación adecuada y oportuna con médicos tratantes y pacientes, de modo que la contribución de las imágenes sea incorporada en el manejo y pronóstico de cada uno de los pacientes.

Debemos cuidar que el objetivo de los Departamento de Radiología y de los radiólogos no sean simplemente maximizar la productividad y la rentabilidad. No podemos asimilar la «mejor práctica» con generar muchos informes o hacer la menor cantidad de errores. La mejor práctica de excelencia implica un sentido más profundo, que incluye encontrar genuino orgullo en el trabajo y una profunda satisfacción de hacerlo de una manera que hace una verdadera diferencia en las vidas de otros, especialmente nuestros pacientes, pero también de colegas, estudiantes e integrantes de nuestro equipo de trabajo.

La verdadera excelencia en un Departamento de Radiología no se puede construir a base de contratos de empleo y servicio, utilizando al radiólogo sólo para ganar dinero, sin lealtad ni sentido de cumplimiento, entornos que proporcionan suelo infértil e incluso hostil en el que la excelencia es poco probable que florezca. Si un paciente requiere que hablemos con un médico tratante sobre un examen, lo debemos hacer; si un médico tratante necesita hablar sobre un caso, tenemos que encontrar una manera de hacerlo, aunque avancemos más lento y, lo más importante, evitemos convertirnos en un "técnico", que piensa y actúa como si su única misión sea interpretar las imágenes correctamente. No debemos olvidar que detrás de cada imagen se encuentra un paciente real y un médico referente, que necesitan nuestra ayuda, visualizando así el contexto humano en el que se encuentra la imagen que debemos informar, lo que nos llevará a proporcionar las interpretaciones y recomendaciones que puedan ser útiles para las necesidades de cada paciente en particular.

Los exámenes y procedimientos en los que los radiólogos actúan de forma presencial, especialmente ultrasonografías, procedimientos intervencionales, seriografías y otros, nos otorgan una invaluable oportunidad de disfrutar en directo la relación médico-paciente y también de hacer más visible el rol de los radiólogos en el cuidado de los pacientes, lo que redunda en una mayor valoración de la especialidad de Radiología.

El desarrollo tecnológico plantea nuevos desafíos, cada uno con ventajas y desventajas, para pacientes y radiólogos. La teleradiología, por ejemplo, por una parte,0 mejora el acceso global de los servicios de salud a los radiólogos y representa una fuente de ingresos para éstos, pero también puede promover la comoditización de la Radiología, disminuyendo la valoración profesional de los radiólogos, y prácticamente aboliendo la relación de clínicos y radiólogos que, sin duda, en otro contexto agrega valor a la información certera que el paciente requiere.

Como conclusión podemos decir que toda disciplina médica, no importa cuán tecnológicamente sofisticada sea e incluso a veces alejada del contacto directo con los pacientes, debe preocuparse prioritariamente del cuidado de los seres humanos, nuestros pacientes, porque solo así podremos realmente lograr excelencia en la práctica médica, en nuestro caso de la práctica radiológica.

\section{Lectura sugerida}

1. Gunderman R, Brown B. Excellence and Professionalism in Radiology. AJR 2013; 200: W557-W559.

2. Hryhorczuk A, Hanneman K, Eisenberg R, Meyer E, Brown S. Radiologic Professionalism in Modern Health Care. RadioGraphics 2015; 35:1779-1788.

3. Rodríguez J. Profesionalismo médico: Aspectos históricos y religiosos. Rev Méd Chile 2006; 134: 381-384.

4. Halpern E, Spandorfer J. Professionalism in Radiology: Ideals and Challenges. AJR 2014; 202: 352-357.

Moënne K. Profesionalismo en el ejercicio de la Radiología. Rev Chil Radiol 2017; 23(4): 193-194. Correspondencia: Karla Moënne B. I kmoenne@clinicalascondes.cl

Trabajo enviado el 14 de noviembre de 2017. Aceptado para publicar el 09 de diciembre de 2017. 